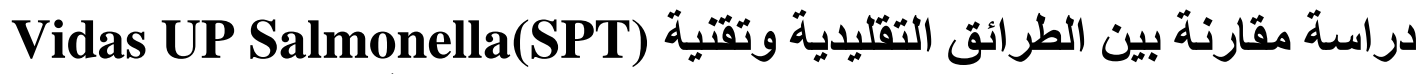 للتحري عن بكتريا السالمونيلا من اللحوم المحلية والمستوردة لفئة
}

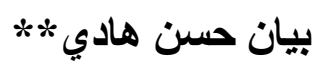

\author{
علياء عبد الحسين كاظم*
}

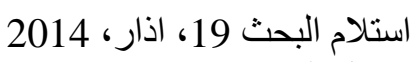

منى تركي الموسوي*

(c) (i) () $\odot$

قبول النشر 26، ايار ، 2014

NoDerivatives 4.0 International Licens

أجريت الدراسة لغرض التحري عن بكتريا السالمونيلا من اللحوم ، ومقارنة الطر ائق التقليدية بتقنية Vidas UP Salmonella(SPT)

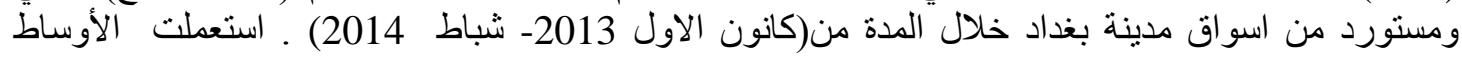

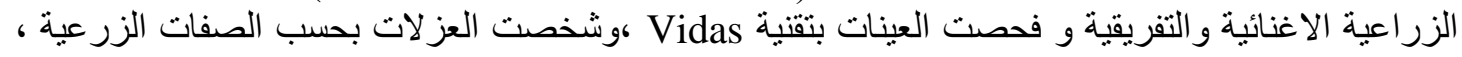

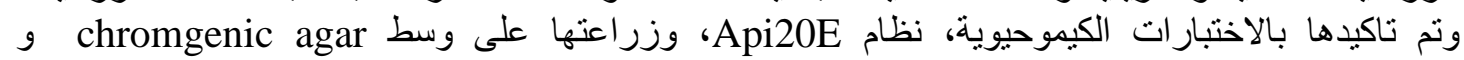

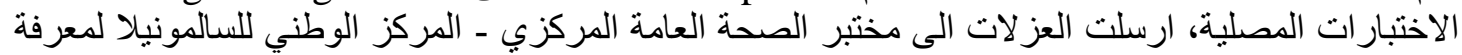

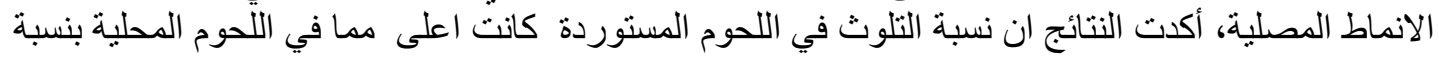

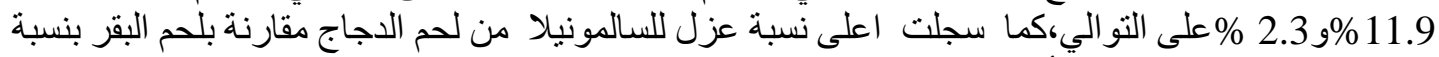

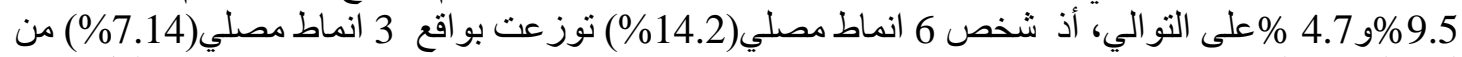
لحم الدجاج المستورد تضمنت

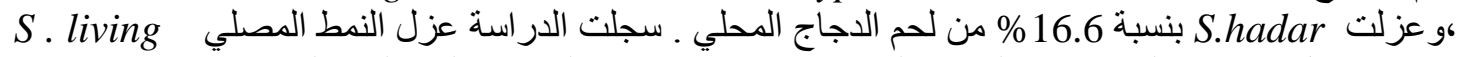

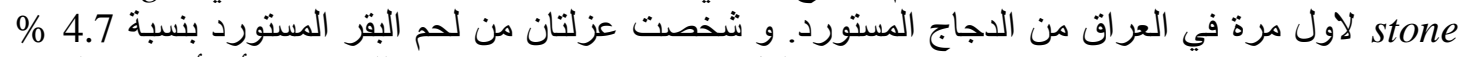

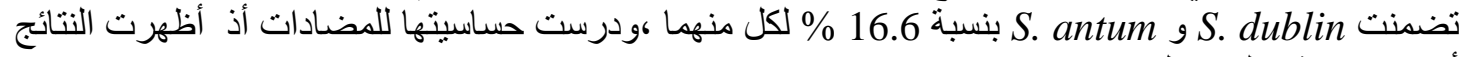
أنها مقاومة الى كل من Chloromphenicol, Ampicillin Cetazidime Trimethprime

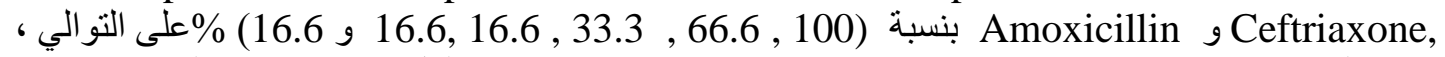

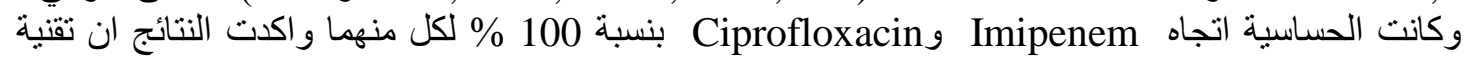
افضل من الطر ائق التقليدية لسر عتها ودقتها في الكثف عن السالمونيلا في العينات الغذائية .

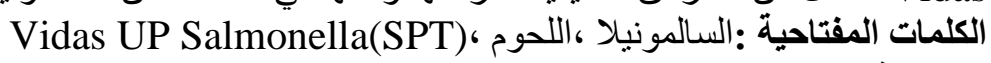

الجرثومة. [3]. ومن الطر ائق المستعملة للكثف

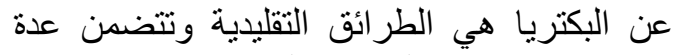

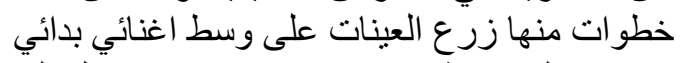

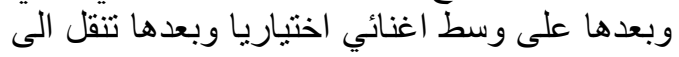

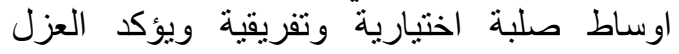

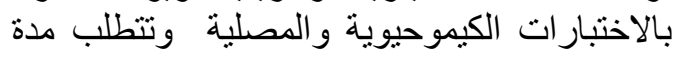

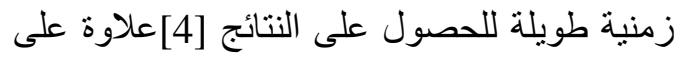
ذلك العوامل البيئية قد تسبب اختلافا في تعبير جين الكين

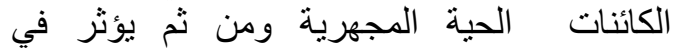
الاختبارات الكيموحيوية [5] اما الطريقة السريعة فئة الكئة البديلة للكثف عن السالمونيلا في العينات الغذائية

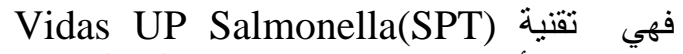
و هي تقنية أنوماتيكية حديثة معتمدة على المقاييس

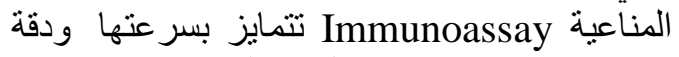

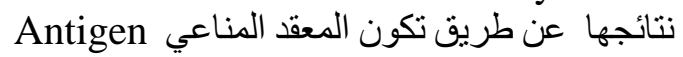
Vidas Antibody Conjection

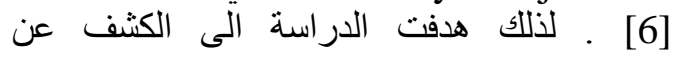
السالمونيلا من اللحوم الطرائق التقليدية وبتقنية Vidas UP Salmonella(SPT) بينهما ودر اسة مقاو متها للمضـادات الحيوية.
يعد اللحم وسطّا جيدا لنمو ونقل السالمونيلا

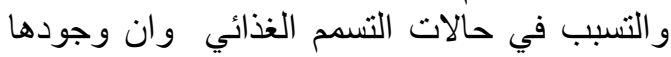

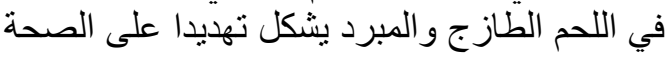

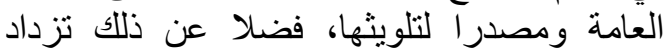

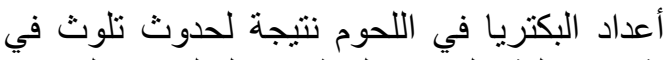

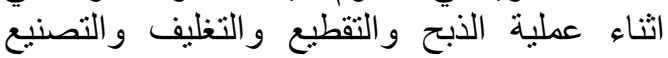
وظروف الخزن الليئة في غرف التئ والتبريد وعملية

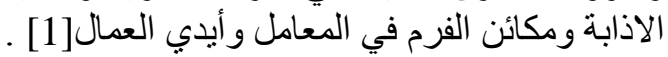

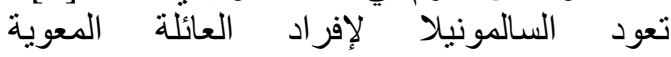
Enterobacteriaceae

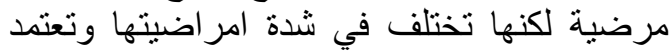

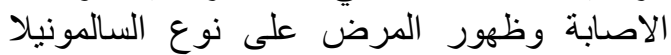

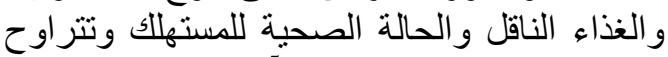
الجرعة المرضية بين 10-105 الفية (وحدة تكون

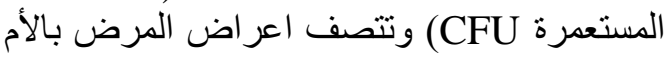

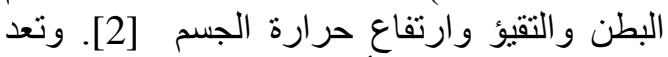

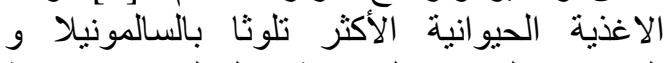

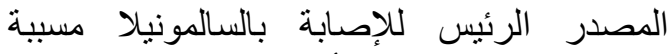

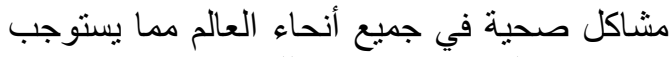

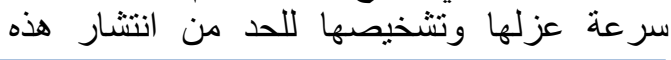

* جامعة بغداد/كلية العلوم للبنات/قسم علوم الحياة 
الكو اشف في حين كانت النتيجة سالبة عند عدم تغير Api profile اللون بعد مقارنة النتائج بدليل النيل index

الفحوصات المصلية Serological Test اجري اختبار التلازن على الثريحة الزجاجية باستعمال مصول Slide aggulutination مضادة قياسية للمستضدين الجسمي والسوطي )

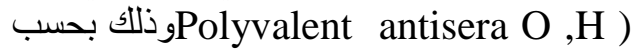
طريقة [10]بوضع ثلاث قطر ات من محلول الملح

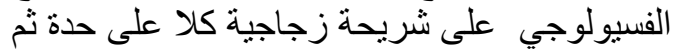
نقل جزء من المستعمرات البكترية بوساطة زلية الناقل واضيفت قطرة من المصل المضندادة القياسي

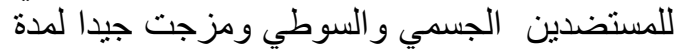

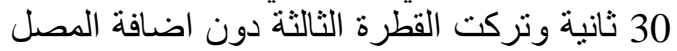

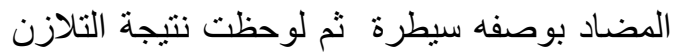

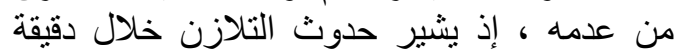

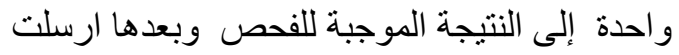

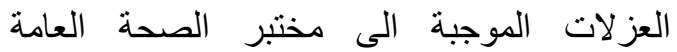

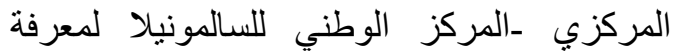
الانماط المصلية.

فحص الحساسية للمضادات الحياتية Bacterial Antibiotic Sensitivity Test الجري فحص الحساسية باستعمال طريقة

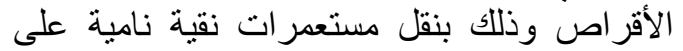
وسط الاكار المغذي بوساطة ناقل ميكروبي إلى نالى

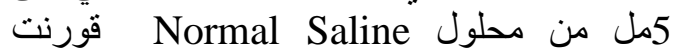
عكورة العالق بعكورة محلول ثابت العكورة

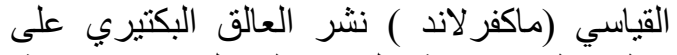

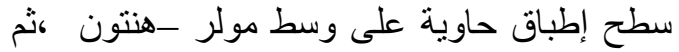

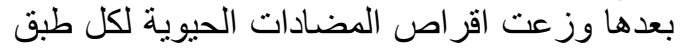

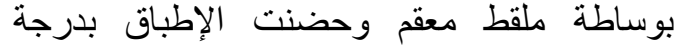
حرارة37م ولمدة 18-24ساعة وسجلت النتائج بقياس قطر التثبيط حول كل قرص واستة واستعملت السلالة القياسية 25922 ATCC للمقارنة بحسب ما وردد في [11] - مالمين

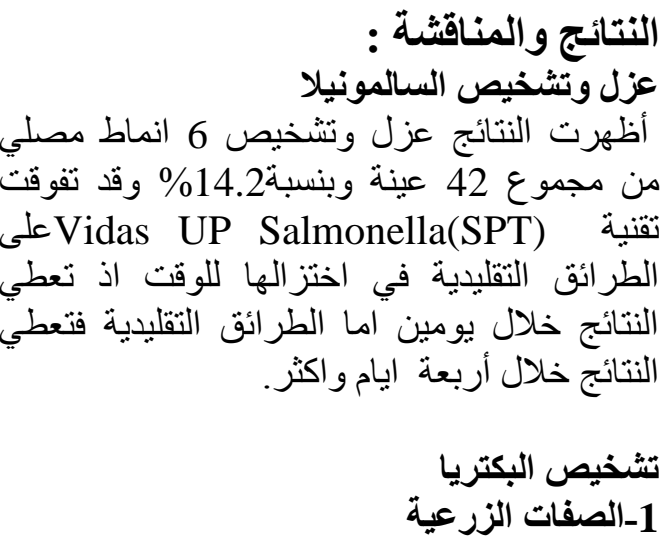
تمايزت مستعمر ات بكتريا السالمونيلا كما مبين في جدول وشكل -1- [12] - جنيزت

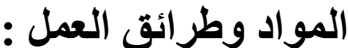
جمع العينات جمعت 42 عينة من اللحوم المحلية والمستوردة في

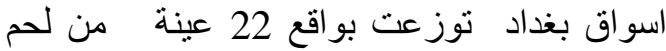

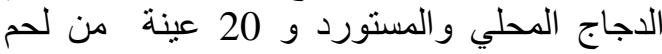
البقر المحلي والمستورد خلال المالمدة المدة من كانون الاول 2013 ولغاية شباط 2014.

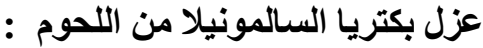
وزنت25 غم من كل عينة وأضيف إلى فئل 225 مل

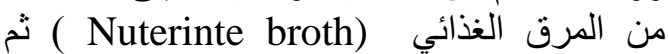
حضنت بدرجة حرارة 37 مق ولمدة 18-24 ساعة ثم نقل 1 مل الى وسط حرارة Tetrathionate broth Selenite cystine broth(SCB) , TTB وبعد نمو البكتريا زرعت على الاوساط الصلبة(MacConkeyagar

- Deoxychoglate(XLD) blood agar Salmonella differential agar

Hicrome agar ,Chrom agar TM (Salmonella

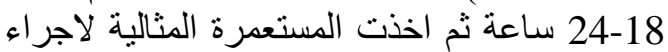

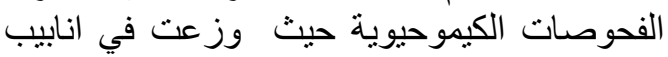
الاختبار الكاشفة Lysine Iron agar حرارة37م ولمدة218 -24ساعة وبحسب ما ورد

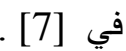
عزل بكتريا السالمونيلا استعمال تقنية Vidas Up Salmonella( SPT) استعملت الطريقة المتبعة من قبل [8] باستخدام

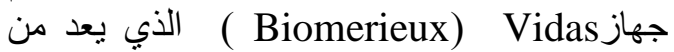
احدث الأجهزة في تشخيص السالمونيلا من الاغذية العية

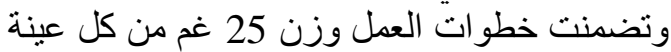
من اللحوم في ظروف معقمة و واضيف 225 مل من

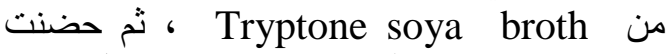
بدرجة حر ارة 37 م لمدة 18-24 ساعة ونقل منه 3 مل بوساطة الماصة

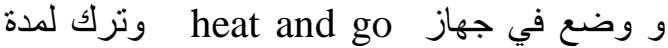
10-6 دقائق ثم برد لمدة 10 دقائق أخذ منه 500

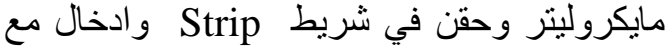

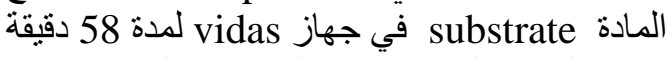
قرئت النتيجة التي ظهرت على شاشة الجهاز .

Microscopic test الفحص المجهري

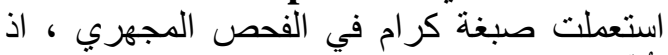

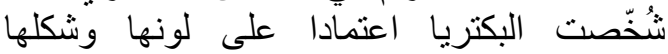

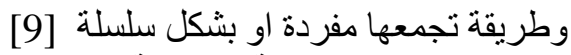
الفحوصات الكيموحيوية التاكيدية بنظام Api-20

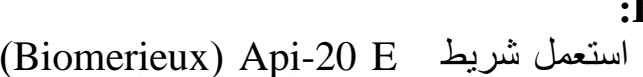

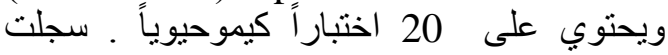

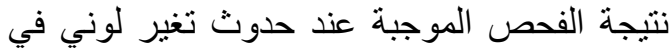
انابيب الثريط بعد انتهاء مدة الحضن واضن واضافة 
جدول (1) الصفات المظهرية للسالمونيلا على الاوساط الزرعية

\begin{tabular}{|c|c|}
\hline الأوساط الزرعية Culture media & الصفات المظهرية Morphology of colonies \\
\hline Xylose-Lysine Deoxycholate agar XLD & دائرية ، ذات حافات ملساء، شاحبة اللون ، مركز اسود نتنجة انتاج كبريت الهيلرورجين \\
\hline وسط الكرومو جينك Hicrome agar & لدائرية ، ذات حافات ملساء ، سو داء اللون اللون ، مرتفعة \\
\hline Salmonella differential agar & لدائرية ، ذات حافات ملساء ، وردية اللون ، مرتفعة \\
\hline CHromagar ${ }^{\mathrm{TM}}$ Salmonella & لدائرية ، ذات حافات ملساء ، بنفسجي اللون ، مرتفعة \\
\hline وسط الماكونكي MacConkey agar & ل دائرية ، ذات حافات ملساء ، اصفر شففاف \\
\hline وسط الدم Blood agar & لمائرية ، ذات حافات ملساء ، شاحبة اللون \\
\hline
\end{tabular}
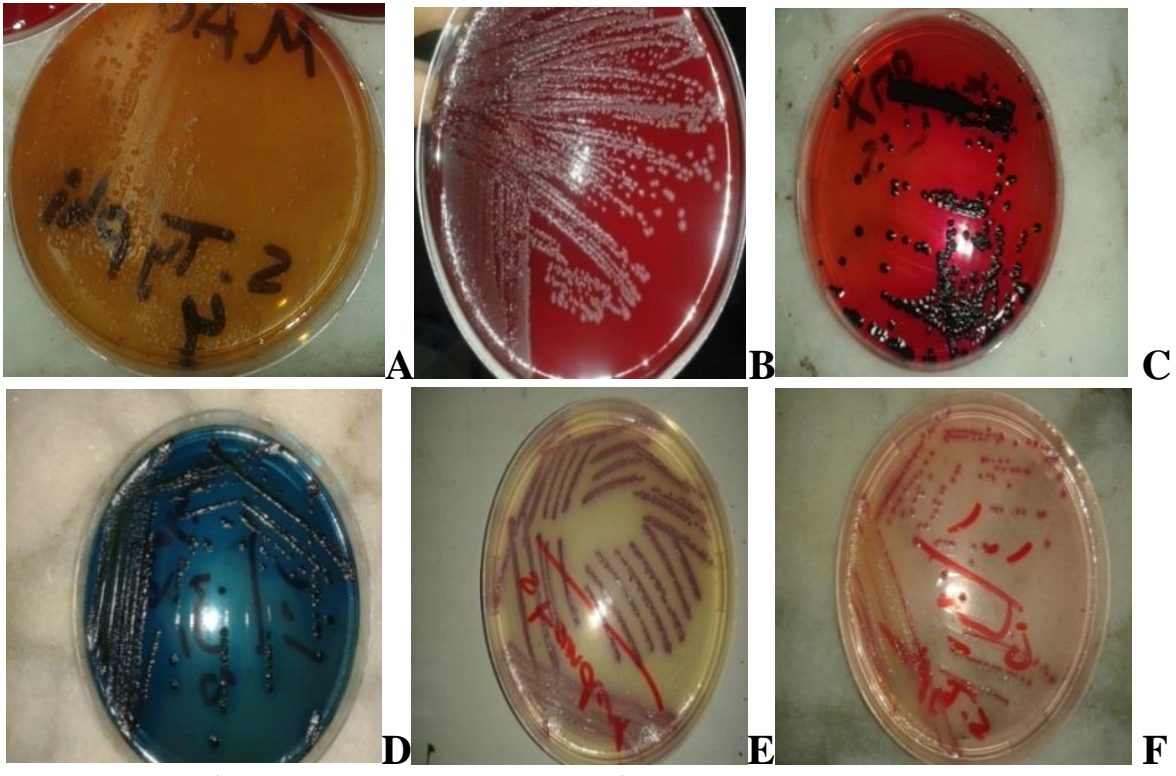

شكل (1)الصفات المظهرية للبكتريا على الاوساط الزرعية

A-MacConkey agar/ B- Blood agar C-XLD / D- Hicrome agar

E- Chrom agar ${ }^{\mathrm{TM}}$ Salmonella / F- Salmonella differential aga

4- الفحوصات الكيموحيوية التاكيدية بنظام - Api

:20 E

كانت جميع العزلات مطابقة للسالمونيلا كما في

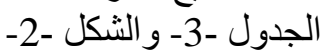

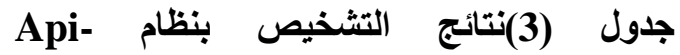
20Esystem لبكتريا السالمونيلا

\begin{tabular}{|l|c|}
\hline \multicolumn{1}{|c|}{ Biochemical test } & Results \\
\hline Lysine Decarboxylase LDC, Ornithine & \\
Decarboxylase ODC, Citrate utilization CIT, & \\
$\mathrm{H}_{2}$ S production, glucose fermentation/ & \\
oxidationglucose GLU,Mannitol MAN , & \\
Inositol INO, Sorbitol SOR, Rhaminose RHA, & + \\
$\begin{array}{l}\text { Melibiose MEL and Arabinose ARA, } \\
\text { Arginine Dehydrolase ADH }\end{array}$ & \\
\hline $\begin{array}{l}\text { (ONPG) Ortho-nitro-phcenyl-galactoside, } \beta- \\
\text { galactosidase urease URE, gelatinase GEL, } \\
\text { Tryptophane deaminase TDA, fermentation / } \\
\text { oxidation of these sugars sucrose SAC, } \\
\text { Amygdaline AMY, Indol IND,VP acertoin } \\
\text { production, oxidase OX }\end{array}$ & \\
\hline
\end{tabular}

2-الفحص المجهزي:

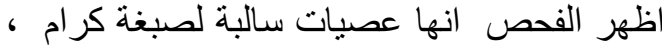

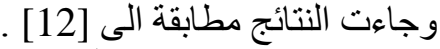

$$
\text { 3-الفحوصات الكيموحيوية }
$$

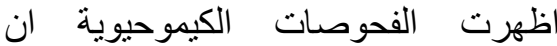

العز لات تعود لجنس السالمونيلا كما مبينة بالجدول الفيولية

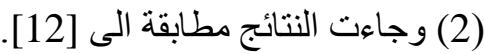

جدول(2) نتائج الاختبارات الكيموحيوية لبكتريا

\begin{tabular}{|c|c|}
\hline النتانج & $\begin{array}{l}\text { الاختبارات الكيموحيوية } \\
\text { Biochemical test }\end{array}$ \\
\hline+ & 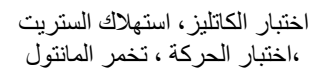 \\
\hline - & اختبار الاوكسديز ، اختبار الاندول ، اختبار اليوريز \\
\hline لون اصنتاجر كبر مخيدرة للكملوكوز للاكتوز / لهيدروجين & $\begin{array}{c}\text { Kligler - Iron اختبار الكلكلر } \\
\text { agar }\end{array}$ \\
\hline 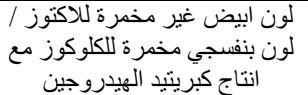 & $\begin{array}{c}\text { Lysine- Iron ختبار الليسين } \\
\text { agar }\end{array}$ \\
\hline
\end{tabular}
السالمونيلا 
[18]. وييين (الجدول 4) عزل نمطين مصلين من

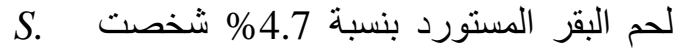

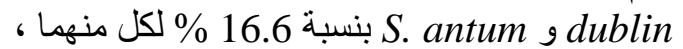

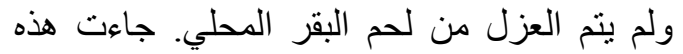

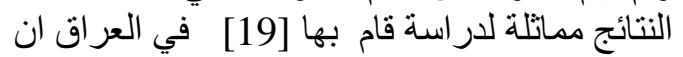

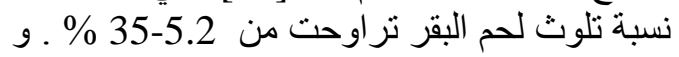

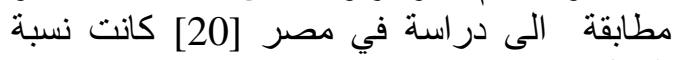
العزل فيها 5.3 \%

جدول (4) الانماط المصلية للسالمونيلا المعزولة

\begin{tabular}{|c|c|c|c|}
\hline \multicolumn{4}{|c|}{ من اللحوم المتداولة في اسواق بغداد } \\
\hline $\begin{array}{l}\text { العداد } \\
\text { (\%) }\end{array}$ & 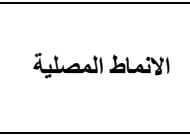 & 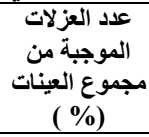 & نوع (العدد) \\
\hline- & - & (0) 0 & لحم بقر المحلي \\
\hline (16.6) 1 & S. dublin & \multirow{2}{*}{ (20 2} & \multirow{2}{*}{ مستورد هندي (10) } \\
\hline (16.6) 1 & S. anatum & & \\
\hline (16.6) 1 & S. hadar & (10 ) 1 & محلي(10) دجاج \\
\hline (16.6) 1 & S.typhimurium & \multirow{3}{*}{$(25) 3$} & \multirow{3}{*}{ 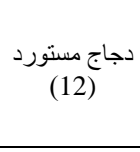 } \\
\hline (16.6) 1 & S.entertidis & & \\
\hline (16.6) 1 & S. living stone & & \\
\hline & (100) 6 & $(14.2) 6$ & المجموع (42) \\
\hline
\end{tabular}

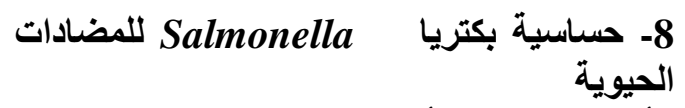

أظهرت النتائج أن السالمونيلا كانت مقاومة لكل

Cetazidime Trimethprime من Chloromphenicol, Ampicillin , Amoxicillin , Ceftriaxone, (16.6 16.6, 16.6, 33.3 , 66.6 100) \% على التو الي ، وكانت حساسة Imipenem

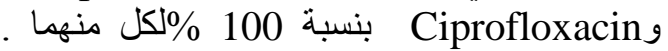
وكما موضح في الجدول (5). اذ ذكر [21] ان سبب النيب

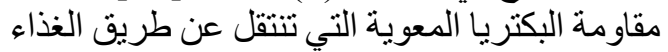

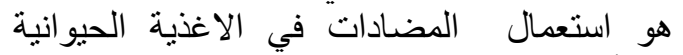

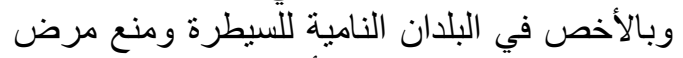
Salmonellosis المقاومة للمضادات وحدوث طفرات. و اتفقت هذه زئه

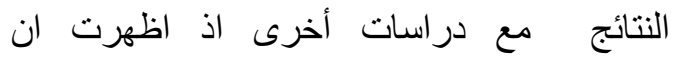

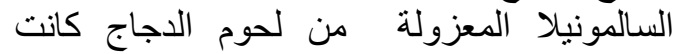

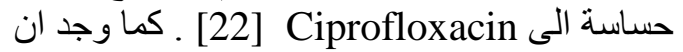
السالمونيلا المعزولة من عينات اللحوم حساسة الى الى كانى Ciprofloxacin

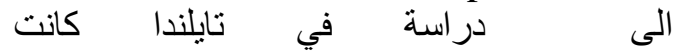
مقاومة Chloramphenicol من قبل عزلاتلات من لحوم الدجاج بنسبة 18.18\% [24 ].

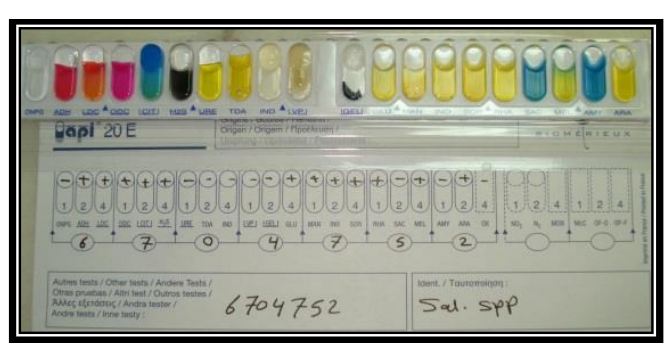

Api 20 E شكل (2)تثخيص البكتريا بنظام

Vidas UP التثخيص بتقتية 5-5

Salmonella(SPT)

على الرغم من استعمال الطرائق التقليدية في الكثف عن السالمونيلا الا انه يتم حديثا استعمال تقنية Vidas UP Salmonella(SPT) وهي الميكي تقنية اتوماتيكية وتعمل على اقتران المستضد

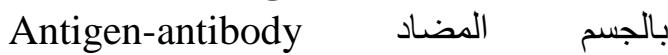
موجية conjunction موجبة من مجموع 42 عينة بنسبة 14.2\%

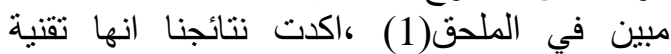
تمايزت بسر عتها ودقة نتائجها وسهولة استعمالها

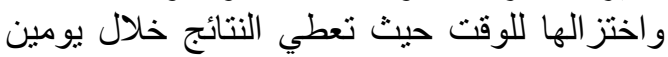
وقلة احتمالية حدوث تلوث في في العينة لكنها تكون

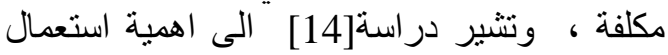
هذه التقنية الحديثة في التحري عن السالمونيلا من التئي الغذاء.

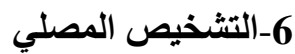

اظهرت النتائج حدوث المهيث التلازن لجميع العزلات

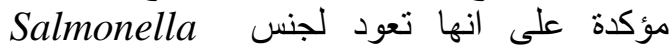

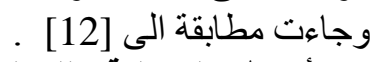

7-الأنماط المصلية للسالمونيلا المعزولة من اللحوم

يبين الجدول (4) الانماط المصلية للسالمونيلا

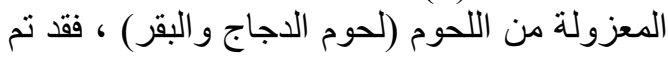

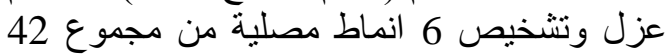

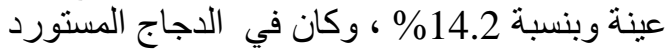

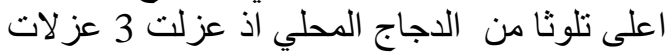
من الدجاج المستورد بنسبة(25\%) شعلت , S.entertidis S.typhimurium S.livingstone , عزل النمط S.hadar بنسبة 10\% من من الاجاج

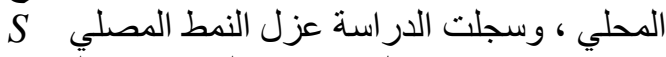

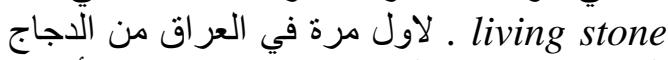

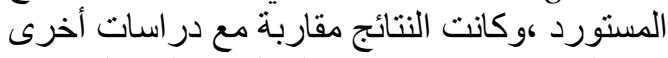

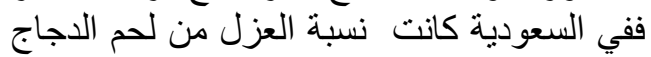

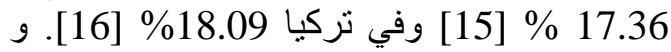

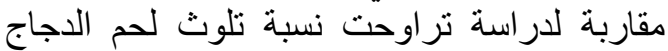

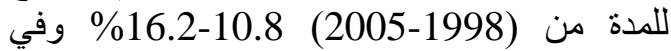

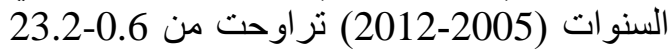
S. hadar S.typhimurium ون ون [17].وفي الأردن كانت نسبة العزل 11.6 \% 


\begin{tabular}{|c|c|c|c|c|c|c|c|c|}
\hline \multirow{2}{*}{ الأنماط المصلية المعزولة من لحوم الاجاج } & \multicolumn{8}{|c|}{ عدد الانماط الحساسة او المقاومة ( النسب المئوية \%\%) } \\
\hline & AMP & CIP & CAS & $\mathrm{C}$ & IMP & CRO & AMC & TS \\
\hline S.typhimrium & $\mathrm{R}(33.3)$ & $\mathrm{S}(100)$ & $\mathrm{R}(66.6)$ & S (83.3) & S100 & R 16.6) & R 16.6) & $\mathrm{R}(100)$ \\
\hline S.livingstone & $\mathrm{S}(66.6)$ & $\mathrm{S}(100$ & $\mathrm{R}(66.6)$ & $\mathrm{S}(83.3)$ & $\mathrm{S}(100$ & $\mathrm{S}(83.3)$ & $\mathrm{S}(83.3)$ & $\mathrm{R}(100)$ \\
\hline S.entertidis & $\mathrm{S}(66.6)$ & $\mathrm{S}(100$ & $\mathrm{R}(66.6)$ & $\mathrm{S}(83.3)$ & $\mathrm{S}(100$ & $\mathrm{S}(83.3)$ & $\mathrm{S}(83.3)$ & $\mathrm{R}(100)$ \\
\hline S.hadar & $\mathrm{S}(66.6)$ & $\mathrm{S}(100$ & $\mathrm{R}(66.6)$ & $\mathrm{S}(83.3)$ & $\mathrm{S}(100$ & $\mathrm{S}(83.3)$ & $\mathrm{S}(83.3)$ & $\mathrm{R}(100$ \\
\hline الأنماط المصلية المعزولةً من لحوم البقرّ & & & & & & & & \\
\hline S.anatum & $\mathrm{S}(66.6)$ & $\mathrm{S}(100$ & $\mathrm{S}(33.3)$ & R 16.6) & $\mathrm{S}(100$ & $\mathrm{S}(66.6)$ & $\mathrm{S}(83.3)$ & $\mathrm{R}(100$ \\
\hline S.dublin & $\mathrm{R}(33.3)$ & $\mathrm{S}(100$ & $\mathrm{S}(33.3)$ & $\mathrm{S}(83.3)$ & $\mathrm{S}(100$ & $\mathrm{S}(83.3)$ & $\mathrm{S}(83.3)$ & $\mathrm{R}(100$ \\
\hline
\end{tabular}

Manual of systematic Bacteriology. 2 nd Ed. part 2, the Proteobacteria, Springer, 2:207213.

8-International Standards Organization ISO 16140 2003. Microbiology of food and animal feeding stuffgeneral requrimante and guilance for micorbiliogical examination.

9-Jawetz, E. Melnick, J. L. and Adelberg, E.A. 2010. Review of Medical Microbiology. $25^{\text {th }}$.ed. Mc Craw-Hill Companies. Inc. chap(16).P.258-

260.Chap(10).p.337-340.

10- Collins, C. H.; and Lyne; P. M. 1987. Microbiological Methods. 5 th Ed. Butteworths Co. puplishers Ltd. U.K.

11-NCCLS. 2002. Performance standards for antimicrobial susptibility testing .Twelfth information supplement.

12- Winn, W.J.; Allen, S.D.; Jauda, W.M.; Koneman, E.W.; Procop, G.W.; Schreckenberger, P.C. and Woods, G. L. 2007. " Koneman's " Color Atlas and Text Book of Diagnostic Microbiology. $6^{\text {th }}$ Ed. Chapter 6, Lippincott - Williams and Wilkins Publisher. Philadelphia. Newyork., Pp: 211258.

13- Yeh, K. S.; Tsai, C. E. ; Chen, S. P. and Liao, C. W.. 2002. Comparison between VIDAS automatic enzyme-linked fluorescent immunoassay and culture method for Salmonella A Dangerous Foodborne Pathogen 412 Salmonella recovery from pork carcass sponge samples. J. F. Pro. 65, : 1656-9

\section{References:}

1- Ailsa, D. H. 2003. Food Borne Microorganisms of Public Health Significance. 6 th ed., AIFST. 209255.

2- WHO/FAO World Health Organization and Food and Agriculture of the United Nations. 2002. Risk Assessments of Salmonella in Eggs and Broiler Chickens. Microbiological Risk Assessments Series 2. WHO library publication data.

3- Mrema, N., Mpuchane, S. and Gashe, B.A. 2006. Prevalence of Salmonella in raw minced meat, raw fresh sausages and raw burger patties from retail outlets in Gaborone, Botswana. Food Control. 17: 207-212.

4-International Standards Organization. ISO 6579. 2005. Microbiology of food and animal feeding stuffs horizontal method for the detection of Salmonella spp.

5- Malorny, B.; Tassios, P. T.; Radström, P.; Cook, N.; Wagner, M.; and Hoorfar, J. 2003. Standardization of diagnostic PCR for the detection of foodborne pathogens. J. Int. F. Mic. 83(1), 39- 48.

6- Favrin, S. J.; Jassim, S.A. and Griffiths, M.W. 2003. Application of a novel immunomagnetic separation-bacteriophage assay for the detection of Salmonella enteritidis and Escherichia coli O157: H7 in food. International Journal of Food Microbiology. 85: 63-71.

7- Brenner, D.J.; Krieg, N.R. and Stalely, J.T. 2005. Bergey's 
Master Thesis. Faculty of Science, University of Basra.

20- Abd-Elally, N. S. and Meshref, A. M. S. 2007. Prevalence of Salmonella and E. coli O157: H7 in Some Food. B.S. Vet. Med. (5)7378.

21- Zhao, S.; McDermott, P.F.; White, D.G.; Qaiyumi, S.; Friedman, S.L.; Abbott, J.W.; Glenn, A.; Ayers, S.L.; Post, K.W.; Fales, W.H.; Wilson, R.B.; Reggiardo, C.; and Walker, R.D. 2007. Characterization of multidrug resistant Salmonella recovered from diseased animals. J.Vet. Mic. 123, 122-132.

22- Soufi, L.; Sáenz, Y.; Toro, M.; Abbassi, M.; Bezares, . Vinué, L.; Bouchami, O.; Touati, A.; Hassen, A.; Hammami, S. and Torres ,C.2012. Phenotypic and Genotypic Characterization of Salmonella enterica Recovered from Poultry Meat in Tunisia and Identification of New Genetic Traits. Vector Borne Zoonotic Dis.; 12(1): 10-16.

23-Ali,M.A. and Elmadiena,N.2008. Biochemical, Serological and Molecular Characterization of Salmonella spp. Isolated from Different Sources in Sudan . Journal of Research Microbiology 5(10) 966-976.

24- Akbar, A.; Anal, A. K. 2013. Prevalence and antibiogram study of Salmonella and Staphylococcus aureus in poultry meat. Asian Pac J Trop Biomed. 3(2): 163-168.
14- Martiny, D. ;Busson, L. ;Wybo, I.; Haj, R.A.E.; Dediste, A.; Vandenberg, O., and Microflex ,L.T. 2012. Comparison of the and Vitek MS Systems for Routine Identification of Bacteria by MatrixAssisted Laser Desorption Ionization-Time of Flight Mass Spectrometry J Clin. Microbiol. 50(4): 1313-1325.

15- Saad, A. M.; Al-Mujali, D. M.; Babiker, S. H.; Shuaib, M. A. M.; Abd Elgadir, K. A. and AlFadul, Y. A. 2007. Prevalaence of Salmonella in broiler central region of K.S.A. J. Anim. Vet. Advances. 6(2): 164-167.

16- Goncagol, G.; Gunaydin, E. and Carli, K. T. 2005. Prevalence of Salmonella sero groups in chicken meat. Turk. J. Vet. Anim. Sci. 29: 103-106.

17- USDA-FSIS, United States Department Of Agriculture Food Safety and Inspection Service. 2013. Historical Salmonella Serotype Information Letters For Establishments Producing Ground Chicken And Ground Turkey. Washington, Dc Fsis Notice 22-30

18- Al-Matar,A.H.; Al-Shawabkeh,K. and Zakaria,H.2005. Prevalence of Salmonella in Broiler Chicken Carcasses in Jordan . J. Agr. Sci. (32)2.267-277.

19- Mohammed, M.T. 2009. Molecular detection of S.typhimurium from minced beef in the city of Basra. 


\title{
A comparative study between conventional methods and Vidas UP Salmonella (SPT) to investigate salmonella species from local and imported meat
}

\begin{abstract}
Muna T. AL-mossawei
Beain H. Hadi*

Alyaa A. Kadhim

University of Baghdad, College of Science for Women, Department of Biology.

* The Central Public Health Laboratory.

Abstract:

The study was preformed for investigating of Salmonella from meat, and compared Vidas UP Salmonella (SPT) with the traditional methods of isolation for Salmonella, were examined 42 meat samples (Beef and Chicken) from the Local and Imported From local markets in the city of Baghdad from period December 2013 February 2014 the samples were cultured on enrichment and differential media and examined samples Vidas, and confirmed of isolates by cultivation chromgenic agar, biochemical tests ,Api20 E systeme, In addition serological tests, and the serotypes determinate in the Central Public Health Laboratory / National Institute of Salmonella The results showed the contamination in imported meat was more than in the local meat $11.9 \%$ and $2.3 \%$, respectively, also recorded the highest isolation of Salmonella from chicken meat compared with beef meat $9.5 \%$ and $4.7 \%$, respectively, where isolated 3 serotype $(7.14 \%)$ from imported chicken meat include S.typhimurium S.entertidis and S.livingstone at $16.6 \%$ for each of them and 1 serotype $(2.3 \%)$ isolate from local chicken meat include S.hadar $16.6 \%$. The study recorded for the first time isolate of S. living stone in Iraq from imported chicken. While isolated 2 serotype $(4.7 \%)$ isolate from imported beef included S. dublin and S. antum at $16.6 \%$ each of them the sensitivity of antibiotics, was studies the results showed that it was resistant to each of Trimethprime Cetazidime Ampicillin Chloromphenicol, Ceftriaxone, and Amoxicillin (100, 66.6 ,33.3, 16.6 , 16.6, and 16.6 ) \% respectively , but sensitivite to Imipenem and Ciprofloxacin at $100 \%$ and confirmed the results that the Vidas technique better than traditional methods for speed and accuracy of their results.
\end{abstract}

Key words: Salmonella, meat, Vidas UP Salmonella(SPT). 